\title{
A case of Madelung's disease accompanied by Klinefelter's syndrome
}

\section{Aysenur Ozderya, Sule Temizkan, Kadriye Aydin Tezcan, Feyza Yener Ozturk' and Yuksel Altuntas'}

Division of Endocrinology and Metabolic Diseases, Kartal Dr Lutfi Kirdar Training and Research Hospital, 34890 Istanbul, Turkey

${ }^{1}$ Division of Endocrinology and Metabolic Diseases, Sisli Etfal Training and Research Hospital, Istanbul, Turkey
Correspondence

should be addressed

to S Temizkan

Email

suletemizkan@yahoo.com

\section{Summary}

Madelung's disease is a rare fat metabolism disorder characterised by benign multiple symmetric, encapsulated lipomatosis. The exact cause of the disease is unknown; it may be associated with chronic alcoholism and mutations in mitochondrial DNA (A8344G), but there have been cases without these factors reported in the literature. A 29-year-old man with a 6-year history of diabetes mellitus was admitted to our hospital for poorly regulated diabetes and decreased libido. He was not an alcohol consumer. His family history was unremarkable. Physical examination revealed that he had a eunuchoid body shape. There was a symmetric excess fat accumulation in his submandibular, deltoid, nuchal, suprapubic and inguinal areas. He was diagnosed with Madelung's disease, and imaging studies supported the diagnosis. Hormonal evaluation revealed a hypergonadotropic hypogonadism. Karyotype analysis revealed a 47,XXY mutation. Genetic research showed no mitochondrial DNA mutation. Metabolic disorders, such as diabetes mellitus, hyperlipidaemia, hyperuricaemia and liver disease, endocrine gland diseases, such as hypothyroidism, and neurological diseases, such as polyneuropathy and cognitive disorders, may accompany Madelung's disease. The present study represents the first reported case of Madelung's disease accompanied by Klinefelter's syndrome.

\section{Learning points:}

- Madelung's disease is a rare fat metabolism disorder characterised by benign multiple symmetric and encapsulated lipid accumulation.

- The exact cause of the disease is unknown.

- Metabolic disorders, such as diabetes mellitus, hyperlipidaemia, hyperuricaemia and liver disease, endocrine gland diseases, such as hypothyroidism, and neurological diseases, such as polyneuropathy and cognitive disorders, may accompany Madelung's disease.

\section{Background}

Madelung's disease is a rare fat metabolism disorder which is characterised by benign multiple symmetric, encapsulated lipomatosis. It was first described by Brodie in 1846, but Otto Madelung reported the first series of patients in 1888. Madelung's report was followed by a series of 30 cases reported by Launois and Bensaude, so the disease is also called Launois-Bensaude disease (1) (2).

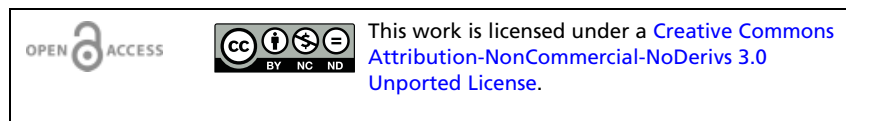

Fat deposits around the neck and shoulder make patients appear 'pseudoathletic'; when the fat deposits are in the parotid region, they make patients look like they have 'hamster cheeks'; when they are around the neck, they look like a 'horse collar'; and when they are on the dorsum of the neck, they look like a 'buffalo hump' (3). Most of the patients affected are middle-aged males. The disorder appears to be more prevalent in Mediterranean countries. The exact cause
(1) 2015 The authors $\quad$ http://www.edmcasereports.com Published by Bioscientifica Ltd 
of the disease is unknown; it may be associated with chronic alcoholism and mutations in mitochondrial DNA (A8344G), but there have been cases without these factors reported in the literature. Although the transformation of lipomas to a malignant tumour is extremely rare, deep infiltration of mediastinal structures with the compression of major vessels, nerves, the trachea, the larynx, bronchi and the oesophagus have been reported (4) (5).

Klinefelter's syndrome is a relatively frequent genetic disease which is characterised by additional $\mathrm{X}$ chromosomes in males $(47, \mathrm{XXY})$. Clinical findings are nonspecific until adulthood, and the diagnosis is commonly made in males that are infertile or have gynaecomastia (6).

Metabolic disorders, such as diabetes mellitus, hyperlipidaemia, hyperuricaemia and liver disease, endocrine gland diseases, such as hypothyroidism, and neurological diseases, such as polyneuropathy and cognitive disorders, frequently accompany Madelung's disease (7) (8). Here, for the first time, we report a case of Madelung's disease accompanied by a genetic disease, Klinefelter's syndrome.

\section{Case presentation}

A 29-year-old male with a 6-year history of diabetes was admitted to our hospital for poorly controlled diabetes and decreased libido. He was thought to have type 1 diabetes mellitus because the onset of his diabetes had occurred early, he had no family history of diabetes, he had lost weight initially and he needed insulin therapy. He was using intensive insulin therapy: $40+26+36$ units insulin lispro and: $32+34$ units insulin detemir. His history revealed that he was not a smoker and not an alcohol consumer. His family history was unremarkable.

Upon admission, a eunuchoid body shape was noticeable, his height was $170 \mathrm{~cm}$, his weight was $72 \mathrm{~kg}$, his waist circumference (WC) was $110 \mathrm{~cm}$ and his BMI was $24 \mathrm{~kg} / \mathrm{m}^{2}$. His blood pressure was $120 / 70 \mathrm{mmHg}$, and his pulse rate was regular at $86 \mathrm{bpm}$. There was a symmetric excess fat accumulation in his submandibular, deltoid, nuchal, suprapubic and inguinal areas (Fig. 1). He had a hepatomegaly, which was revealed by abdominal examination. There was a retardation in his secondary sex characters; upon palpation, his bilateral testes were atrophic, and he had a micropenis $(<7 \mathrm{~cm})$. An extremity examination revealed an oedema and an ulcerative skin lesion on his left leg. His bilateral superficial sensory and deep tendon reflexes were decreased in his lower extremities, which is consistent with diabetic neuropathy. Examination of the fundus showed bilateral nonproliferative diabetic retinopathy and diffuse macular oedema. His other physical and neurological examinations were normal.

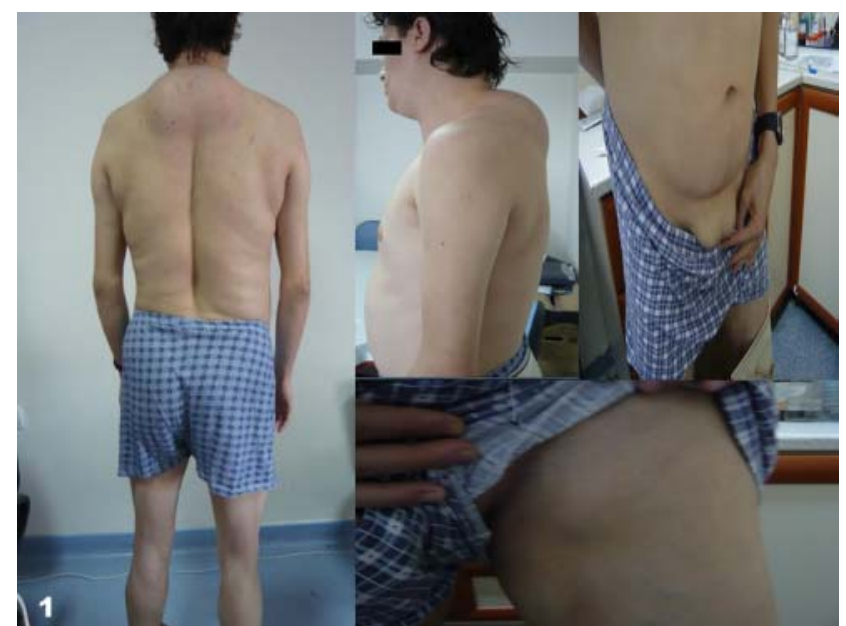

Figure 1

Unusual fat deposits in the nuchal, suprapubic and inguinal regions.

\section{Investigation}

Laboratory examination revealed $423 \mathrm{mg} / \mathrm{dl}$ fasting blood glucose, $14.2 \% \mathrm{HbA1c}, 378 \mathrm{mg} / \mathrm{dl}$ total cholesterol, $158 \mathrm{mg} / \mathrm{dl} \mathrm{HDL}, 4764 \mathrm{mg} / \mathrm{dl}$ triacylglycerols, $18 \mathrm{mg} / \mathrm{dl}$ direct LDL and $9 \mathrm{mg} / \mathrm{dl}$ uric acid. Other biochemical values are detailed in Table 1. Lipoprotein electrophoresis showed hyperprebetalipoproteinaemia ( $\beta$-lipoprotein: $32 \%$ (32-58\%); pre- $\beta$-lipoprotein: 51\% (9-37\%); and $\alpha$-lipoprotein: $14 \%(10-37 \%))$. His urinary albumincreatinine ratio was increased, which is consistent with diabetic nephropathy $(2941 \mathrm{mg} / \mathrm{g})$. His anti-GAD and anti-insulin antibodies were not evaluated.

His hormonal evaluation was concordant with hypergonadotropic hypogonadism (follicle-stimulating hormone: $17 \mathrm{mIU} / \mathrm{ml}$; luteinizing hormone: $14 \mathrm{mIU} / \mathrm{ml}$; and total testosterone: $34 \mathrm{ng} / \mathrm{dl}$ ). His other hormonal values are detailed in Table 1. Scrotal ultrasonography revealed bilateral testicular atrophy and unilateral varicocele. Karyotype analysis showed a 47,XXY mutation.

A cervical MRI examination revealed an encapsulated fat accumulation $\sim 20 \mathrm{~cm}$ in diameter in his nuchal and bilateral supraclavicular area (Fig. 2). Biopsies from these areas were concordant with lipomatous tissue (Fig. 3). An abdominal CT examination revealed an enlarged liver (cranio-caudal axis: $24 \mathrm{~cm}$ ) and spleen. After a differential diagnosis of the causes of the hepatosplenomegaly, a Tru-Cut liver biopsy was made. It revealed a grade 3 macrovesicular steatosis, mild lobular inflammation and mild periportal fibrosis (Fig. 3). An echocardiographic examination was normal. There was an oedema and an 
Table 1 Laboratory investigations.

\begin{tabular}{|c|c|}
\hline & Values \\
\hline \multicolumn{2}{|l|}{ Biochemical analysis } \\
\hline FPG (mg/dl) & 423 \\
\hline Urea (mg/dl) & 28 \\
\hline Creatinine (mg/dl) & 0.7 \\
\hline Uric acid (mg/dl) & 9 \\
\hline Total cholesterol (mg/dl) & 378 \\
\hline Triglyceride (mg/dl) & 4764 \\
\hline LDL cholesterol (mg/dl) & 18 \\
\hline HDL cholesterol (mg/di) & 158 \\
\hline AST (U/I) & 72 \\
\hline ALT (U/I) & 15 \\
\hline GGT (U/I) & 63 \\
\hline LDH (U/I) & 350 \\
\hline Albumin (g/dl) & 4.3 \\
\hline \multicolumn{2}{|l|}{ Hormonal analysis } \\
\hline FSH (1.4-18.1 mlU/ml) & 17 \\
\hline LH $(2.4-12.6 \mathrm{mlU} / \mathrm{ml})$ & 14 \\
\hline Testosterone (241-827 ng/dl) & 34 \\
\hline $\mathrm{E}_{2}(11.6-41.2 \mathrm{pg} / \mathrm{ml})$ & 42 \\
\hline SHBG (13-71 nmol/l) & 7.3 \\
\hline Prolactin $(2.1-17.7 \mathrm{ng} / \mathrm{ml})$ & 3 \\
\hline TSH $(0.55-4.78 \mu \mathrm{lU} / \mathrm{ml})$ & 3.2 \\
\hline Free $\mathrm{T}_{4}(0.7-1.4 \mathrm{ng} / \mathrm{dl})$ & 1.1 \\
\hline Anti-TPO ( $\leq 10 \mathrm{IU} / \mathrm{ml})$ & Negative \\
\hline Anti-Tg ( $\leq 20 \mathrm{IU} / \mathrm{ml})$ & Negative \\
\hline Cortisol $(4.3-22.4 \mu \mathrm{g} / \mathrm{dl})$ & 13.6 \\
\hline C-peptide $(1.1-5.0 \mathrm{ng} / \mathrm{ml})$ & 0.7 \\
\hline \multicolumn{2}{|l|}{$\mathrm{CBC}$} \\
\hline WBC $\left(\mathrm{mm}^{3}\right)$ & 8.2 \\
\hline $\mathrm{Hb}(\mathrm{g} / \mathrm{dl})$ & 11.5 \\
\hline Hct $(\%)$ & 35.2 \\
\hline Plt $\left(\mathrm{mm}^{3}\right)$ & 288 \\
\hline \multicolumn{2}{|l|}{ Urinary analysis } \\
\hline Alb/Crea (mg/g) & 2941 \\
\hline CRP (mg/l) & 12.8 \\
\hline
\end{tabular}

FPG, fasting plasma glucose; AST, aspartate transaminase; ALT, alanine transaminase; GGT, gamma-glutamyl transpeptidase; LDH, lactate dehydrogenase; $\mathrm{FSH}$, follicle-stimulating hormone; $\mathrm{LH}$, luteinizing hormone; SHBG, sex hormone binding globülin; TSH, thyroid stimulating hormone; TPO, thyroid peroxidase; $\mathrm{Tg}$, thyroglobulin; WBC, white blood cell count; $\mathrm{Hb}$, hemoglobin; Hct, hematocrit; Plt, platelet; CRP, C-reactive protein.

ulcerative skin lesion on his left leg, so an arterial and venous vascular Doppler ultrasonographic examination was made. There were no arterial or venous lesions. An electroneuromyography (EMG) examination showed polyneuropathy, which is consistent with bilateral sensory and motor fibre involvement. Genetic research showed no mitochondrial DNA (A8344G) mutation.

\section{Treatment}

Upon admission, we gave the patient fenofibrate for hyperlipidaemia, and we began testosterone replacement therapy.

\section{Outcome and follow-up}

In a 3-year follow-up after the testosterone replacement therapy had begun, the patient's blood glucose levels were more favourable and his $\mathrm{HbA} 1 \mathrm{c}$ had decreased to $7.5 \%$, but his subcutaneous excess fat deposits had not changed. We did not implement any surgical procedures. His triacylglycerol values had decreased to $507 \mathrm{mg} / \mathrm{dl}$. He did not have a pancreatitis attack.

\section{Discussion}

Madelung's disease is a rare disorder which is characterised by an unusual benign symmetric accumulation of fat tissue on the neck and shoulders. The exact cause is unknown; chronic alcoholism is responsible in $60-90 \%$ of cases, but cases without a history of alcohol consumption have also been reported (9) (10) (11) (12). Alcohol consumption is known to promote lipogenesis and to decrease lipolysis. In addition, alcohol is known to affect mitochondrial metabolism directly and can cause premature oxidative ageing of mitochondrial DNA (13). Additionally, a mutation of mitochondrial DNA (A8344G) associated with Madelung's disease has been reported (14) (15). The patient in the present study had no history of chronic alcohol consumption and no mitochondrial DNA (A8344G) mutation. He had a history of diabetes mellitus and hypergonadotropic hypogonadism, and he was diagnosed with Klinefelter's syndrome by karyotype analysis. This is the first case of Madelung's disease accompanied by Klinefelter's syndrome, but we cannot state whether there is a shared genetic or metabolic basis for the two diseases or whether they

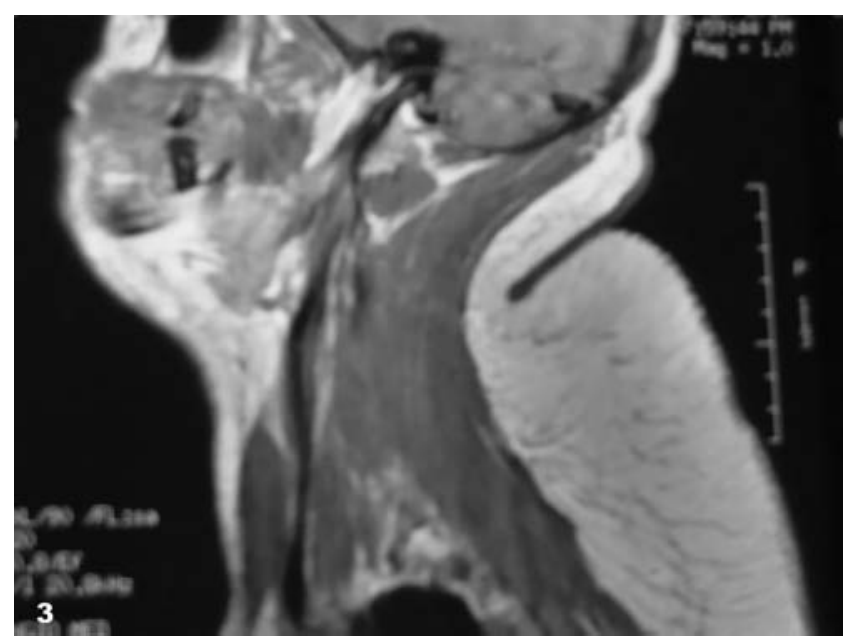

Figure 2

Magnetic resonance image of cervical region, sagittal section. 

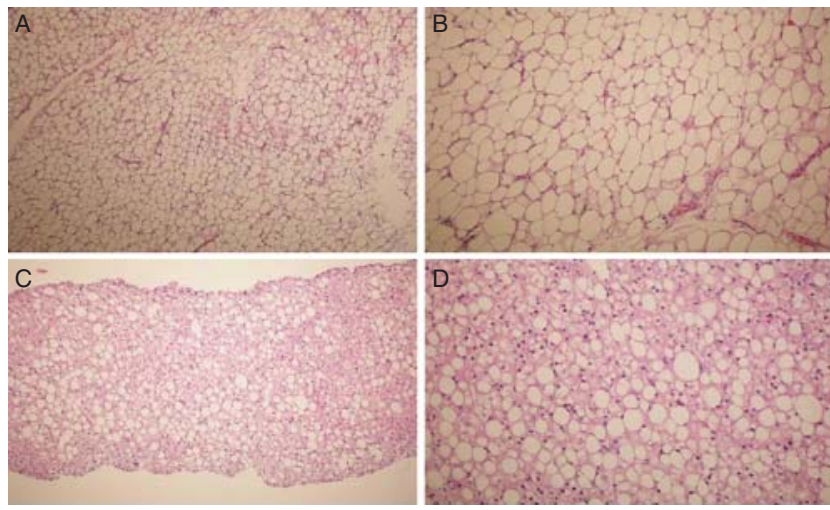

Figure 3

(A) Histopathological examination of the fat tissue. Mature adipocytes (H\&E, $4 \times 10)$; (B) histopathological examination of the fat tissue. Mature adipocytes (H\&E, 10×10); (C) grade 3 macrovesicular steatosis in hepatocyte cytoplasm (H\&E, $4 \times 10)$; (D) grade 3 macrovesicular steatosis in hepatocyte cytoplasm (H\&E, $10 \times 10)$.

randomly co-occurred. Klinefelter's syndrome is a sex chromosome abnormality. There has only been one study about mitochondrial DNA polymorphism in Klinefelter's syndrome and the possible interaction of the sex chromosome and the mitochondrial DNA (16). It has been well established that the incidence of diabetes is increased in Klinefelter's syndrome (10-39\%) because of hypogonadism (6). Hypogonadism may trigger type 2 diabetes by increasing abdominal adiposity in this syndrome and in males with normal karyotype (17). In the present case, uncontrolled diabetes might have affected mitochondrial function. Hyperglycaemia is typically accompanied by the increased production of free radicals, reactive oxygen species which can cause an injury in mitochondrial functions (18).

The main diagnostic procedure of Madelung's disease is clinical and is based on the typical fat tissue distribution on the neck and shoulders, but MRI, CT and biopsy may also be helpful. There are two types of Madelung's disease that differ in terms of the fat distribution on the body. In type 1 , fat accumulates around the neck and on the back of the neck, shoulders, upper arms and upper part of the thorax, giving the patient a 'pseudoathletic' appearance. In type 2, fat tissue extends over the body, including around the hips and thighs, giving the patient a generalised obese appearance (19). The present patient had fat accumulation in the bilateral submandibular, deltoid, nuchal, suprapubic and inguinal areas. Histologically, unlike lipomas, the fat tissue in Madelung's disease is non-encapsulated, with extension into surrounding structures. The patient's MRI examinations and a biopsy of the lesions on his cervical region were concordant with Madelung's disease.

Metabolic disorders and diseases like diabetes mellitus, hyperlipidaemia, hyperuricaemia and liver disease, which may be also associated with alcoholism, generally accompany Madelung's disease. Although the patient was not a drinker, he did have liver disease presented by hepatosplenomegaly. Liver biopsy showed grade 3 macrovesicular steatosis, mild lobular inflammation and mild periportal fibrosis. We thought the liver disease was part of the Madelung's disease and also a result of the patient's uncontrolled diabetes. He had a severe hypertriglyceridaemia, which is consistent with hyperprebetalipoproteinaemia on lipid electrophoresis.

In a differential diagnosis of Madelung's disease, the following entities must be considered: angiolipoma, neurofibroma, encapsulated lipomas, hibernoma, liposarcoma, lymphatic tumours, salivary gland disorders and Dercum disease (20).

Treatment of Madelung's disease consists of the surgical removal of the fatty deposits from the areas around the head, neck, shoulders and trunk. Liposuction has been used successfully to remove single fatty tumours. The present patient requested surgery, but it was not implemented because of his uncontrolled diabetes. It has been shown that testosterone treatment of hypogonadal patients with type 2 diabetes may improve insulin sensitivity (21). We experienced this in the present case with more favourable blood glucose levels after testosterone replacement therapy.

In summary, cases with Madelung's disease in the literature are mostly the result of alcoholism, but the present patient was not a drinker and had no mitochondrial DNA mutation. He had a diagnosis of Klinefelter's syndrome, which has not been described in association with Madelung's disease in the previous literature.

Declaration of interest

The authors declare that there is no conflict of interest that could be perceived as prejudicing the impartiality of the research reported.

\section{Funding}

This research did not receive any specific grant from any funding agency in the public, commercial or not-for-profit sector.

\section{Patient consent}

Written informed consent was obtained from the patient for the publication of the present case report and its figures. 


\section{Author contribution statement}

A Ozderya was the principal investigator and clinically followed the patient; S Temizkan, $\mathrm{K}$ Aydin Tezcan and $\mathrm{F}$ Y Ozturk contributed to the acquisition and analysis of the data; S Temizkan drafted the article; Y Altuntas revised the article.

\section{References}

1 Brodie BC 1846 Clinical Lectures on Surgery Delivered at St. George's Hospital. Philadelphia: Lea \& Blanchard. 201-210.

2 Madelung OW 1888 Über den Fetthals (diffuses Lipom des Halses). Archiv für klinische Chirurgie 37 106-130.

3 Josephson GD, Sclafani AP \& Stern J 1996 Benign symmetric lipomatosis (Madelung's disease). Otolaryngology and Head and Neck Surgery 115 170-171. (doi:10.1016/S0194-5998(96)70159-6)

4 Tizian C, Berger A \& Vykouph K 1983 Malignant degeneration in Madelung's disease. British Journal of Plastic Surgery 36187. (doi:10.1016/0007-1226(83)90089-9)

5 Gonzalez-Garcıa R, Rodrıguez-Campo FJ, Sastre-Perez J \& Munoz-Guerra MF 2004 Benign symmetric lipomatosis (Madelung's disease): case reports and current management. Aesthetic Plastic Surgery 28 108-112.

6 Groth KA, Skakkebæk A, Høst C, Gravholt CH \& Bojesen A 2013 Clinical review: Klinefelter syndrome - a clinical update. Journal of Clinical Endocrinology and Metabolism 98 20-30. (doi:10.1210/jc.2012-2382)

7 Teplitsky V, Huminer D, Dux S, Learman Y, Zoldan J \& Pitlik SD 1995 Multiple symmetric lipomatosis presenting with polyneuropathy. Israel Journal of Medical Sciences 31 693-695.

8 Yeh NC, Yang CY, Chou CW, Yen FC, Lee SY \& Tien KJ 2012 Madelung's disease. Journal of Clinical Endocrinology and Metabolism 97 3012-3013. (doi:10.1210/jc.2012-1649)

9 Kohan D, Miller PJ, Rothstein SG \& Kaufman D 1993 Madelung's disease: case reports and literature review. Otolaryngology and Head and Neck Surgery 108 156-159.

10 Morinaka S, Sato T, Miyoshi H \& Iwashita K 1999 A case of multiple symmetrical lipomatosis (Madelung's disease). Auris, Nasus, Larynx 26 349-353. (doi:10.1016/S0385-8146(99)00007-3)

11 John DG, Fung HK, van Hasselt CA \& King WW 1992 Multiple symmetrical lipomatosis in the neck. European Archives of Oto-Rhino-Laryngology 249 277-288. (doi:10.1007/BF00714492)
12 Enzi G, Busetto L, Ceschin E, Coin A, Digito M \& Pigozzo S 2002 Multiple symmetric lipomatosis: clinical aspects and outcome in a long-term longitudinal study. International Journal of Obesity and Related Metabolic Disorders 26 253-261. (doi:10.1038/sj.ijo.0801867)

13 Kodish ME, Alsever RN \& Block MB 1974 Benign symmetric lipomatosis: functional sympathetic denervation of adipose tissue and possible hypertrophy of brown fat. Metabolism: Clinical and Experimental 23 937. (doi:10.1016/0026-0495(74)90043-2)

14 Gamez J, Playajn A, Andreu AL, Bruno C, Navarro C, Cervera C, Arbs MA, Schwartz S, Enriquez JA \& Montoya J 1998 Familial multiple symmetric lipomatosis associated with the A8344G mutation of mitochondrial DNA. Neurology 51 258-260. (doi:10.1212/WNL.51. 1.258)

15 Lee YC, Wei YH, Lirng JF, Lee HC, Tso DJ, Lin KP, Wu ZA \& Liu HC 2002 Wernicke's encephalopathy in a patient with multiple symmetrical lipomatosis and the A8344G mutation of mitochondrial DNA. European Neurology 47 126-128. (doi:10.1159/000047967)

16 Oikawa H, Tun Z, Young DR, Ozawa H, Yamazaki K, Tanaka E \& Honda K 2002 The specific mitochondrial DNA polymorphism found in Klinefelter's syndrome. Biochemical and Biophysical Research Communications 297 341-345. (doi:10.1016/S0006-291X(02)02198-8)

17 Grossmann M, Thomas MC, Panagiotopoulos S, Sharpe K, Macisaac RJ, Clarke S, Zajac JD \& Jerums G 2008 Low testosterone levels are common and associated with insulin resistance in men with diabetes. Journal of Clinical Endocrinology and Metabolism 93 1834-1840. (doi:10.1210/ jc.2007-2177)

18 Rolo AP \& Palmeira CM 2006 Diabetes and mitochondrial function: role of hyperglycemia and oxidative stress. Toxicology and Applied Pharmacology 212 167-178. (doi:10.1016/j.taap.2006.01.003)

19 Tekin A \& Ogetman Z 2009 Central form of multiple symmetric lipomatosis: a case report. Cases Journal 12 8427. (doi:10.4076/ 1757-1626-2-8427)

20 Ujpal M, Nemeth ZS, Reichwein A \& Szabo GY 2001 Longterm results following surgical treatment of benign symmetrical lipomatosis (BSL). International Journal of Oral and Maxillofacial Surgery 30479. (doi:10.1054/ijom.2001.0162)

21 Heufelder AE, Saad F, Bunck MC \& Gooren L 2009 Fifty-two-week treatment with diet and exercise plus transdermal testosterone reverses the metabolic syndrome and improves glycemic control in men with newly diagnosed type 2 diabetes and subnormal plasma testosterone. Journal of Andrology 30 726-733. (doi:10.2164/jandrol. 108.007005)

Received in final form 27 January 2015

Accepted 1 April 2015 